\title{
O Mercosul no discurso diplomático do primeiro governo Dilma (2011-2014) no contexto bilateral
}

\author{
Alexandre Cesar Cunha Leite \\ Doutor em Ciências Sociais/Relações Internacionais (PUC-SP) \\ Professor da Universidade Estadual da Paraíba \\ Professor da Universidade Federal da Paraíba \\ João Pessoa, Brasil \\ Vinicius Araújo Bezerra \\ Mestre em Relações Internacionais (Universidade Estadual da Paraíba) \\ Campina Grande, Brasil \\ viniciusbe1@hotmail.com
}

O objetivo do artigo é discutir o uso do termo Mercosul no discurso diplomático do primeiro governo Dilma Rousseff (2011 -2014) em um contexto bilateral com os países da América do Sul. A fim de compreender a dinâmica, serão utilizadas diretrizes da Política Externa Brasileira, como Universalismos e Autonomia, e a metodologia da Análise do Discurso, com o intuito de verificar o contexto em que a palavra está inserida, os interlocutores envolvidos e as motivações implícitas e explicitas. O artigo evidenciará que o discurso é um dos meios para a inserção internacional do Brasil.

Palavras-chave: Mercosul, análise do discurso, Política Externa Brasileira, governo Dilma.

\section{Considerações iniciais}

Ao longo de seu primeiro ano de mandato em 2011 até a segunda quinzena de dezembro de 2014, a presidente da República, Dilma Rousseff, fez 713 discursos oficiais sobre os mais variados temas, segundo informações disponíveis no Portal do Palácio do Planalto ${ }^{1}$. Desses pronunciamentos, em 70 deles a palavra Mercosul foi

1 Dados recolhidos entre 2014 e maio/2016. 
mencionada pelo menos uma vez. Dos 70 pronunciamentos proferidos pela representante do Estado brasileiro, 30 ocorreram em um contexto bilateral, ou seja, quando a presidente se pronunciou em encontros com outros chefes de estado, de governo ou algum representante estatal, seja no Brasil ou no exterior. E, por fim, desses 30 discursos, 14 foram proferidos em países da América do Sul.

O objetivo deste artigo é analisar esses 14 discursos oficiais feitos pela presidente da República. Parte-se aqui da premissa de que o representante oficial do Estado brasileiro tem relevância como ator de política externa e como construtor da imagem brasileira no sistema internacional. Pela via da observância sistematizada dos discursos, busca-se identificar até que ponto o uso do termo Mercosul tem sido utilizado como uma plataforma política para a inserção internacional do Brasil no contexto das relações bilaterais com a América do Sul durante o primeiro Governo Dilma Rousseff (2011- 2014).

Para analisar a questão colocada neste artigo, torna-se essencial considerar dois conceitos basilares das diretrizes de Política Externa Brasileira (PEB): autonomia e universalismo. Ainda, é de suma relevância compreender como se deu o uso do Mercosul - como componente da narrativa - considerando a finalidade diplomática de promover a inserção internacional. Partindo do ponto de vista exclusivo do bloco, acordos comerciais não podem ser feitos de forma autônoma por um país à parte do bloco regional, por ser necessário um consenso entre os todos os estados membros. Logo, o Mercosul pode ser utilizado como uma plataforma para inserção ou como um mero artifício de retórica; indagação que se pretende avaliar neste texto.

No que concerne ao universalismo, o Brasil possui essa diretriz desde o advento Política Externa Independente (1961-1964). Esse conceito ajuda a entender como o Mercosul pode ter ao mesmo tempo um caráter regional e universal para a política externa brasileira. O universalismo e a autonomia estão inseridos no discurso diplomático brasileiro proferido pela presidente Dilma quando ela se refere ao Mercosul.

Do ponto de vista metodológico, foi realizada uma coleta de todas as citações da palavra Mercosul, quando mencionada nos discursos oficiais da presidente da República em seu primeiro mandato. Contudo, cabe ressaltar que não foi feita meramente uma coleta de termo, mas complementarmente, uma análise do contexto em que o termo foi empregado. Dessa forma, tem-se um mecanismo mais sincero de leitura que ultrapassa a contagem de uso do termo, mas também qualifica o contexto e tipifica o propósito do seu uso. Assim, foi possível averiguar o contexto em que esse termo estava inserido, as estruturas das frases, o sentido em que foi usada, a quantidade de vezes que foi utilizado, os interlocutores envolvidos, as motivações implícitas e explícitas e as estruturas das frases.

Esta sistematização será exposta e analisada a partir da base metodológica proporcionada pela Análise do Discurso, especialmente a partir da concepção de Milliken (1999), que aponta três meios para compreender a Análise do Discurso nas Relações Internacionais. O primeiro chama a atenção para o fato de que é necessário entender os estudos discursivos como um sistema de significados. Ou seja, eles possuem a capacidade de criar estruturas hierárquicas e ordens, qualificar/desqualificar e identificar. O segundo chama a atenção para 
a incorporação de questões de produtividade. A preocupação aqui é entender como o discurso produz o mundo a partir de seleções de informações. E o terceiro é a questão prática com o objetivo de destrinchar o discurso, para entender os polos em oposição, como ele é explorado pelas fontes, o conteúdo subjugado e observar a perspectiva histórica.

A concepção de Milliken (1999) aproxima-se da construção metodológica construtivista, principalmente às presentes em Onuf (2002) e Kratochwill (1989), uma vez que se considera fundamental compreender as normas e as regras que constroem o discurso, dado ser este um catalisador para a construção social da realidade. Nesse sentido, o discurso, constituído por tais normas e regras, é um instrumento de ação política, pois é por meio dele que se torna possível identificar as regras e as normas da própria realidade. Assim sendo, as Relações Internacionais seriam uma realidade socialmente construída por meio de normas e regras advindas de discursos.

O artigo está estruturado em dois tópicos, além desta introdução e das considerações finais. No primeiro, aborda-se a política externa do primeiro mandato da presidente Dilma Rousseff (2011-2014). A proposta do tópico é descrever e caracterizar o governo Dilma e, principalmente, entender o papel do Mercosul nesse contexto, a partir do universalismo e da autonomia. No segundo tópico, analisa-se os 14 discursos diplomáticos, proferidos pela presidente da República, em que a palavra Mercosul tenha sito citada em um contexto bilateral com os países da América do Sul. A intenção é expor e analisar como o uso da palavra Mercosul instrumentaliza o discurso direcionado para o propósito de promover a inserção internacional do Brasil.

\section{A política externa do primeiro Governo Dilma no Mercosul}

Desde o final do governo de Fernando Henrique Cardoso (FHC) em 2002, quando o debate sobre Área de Livre Comércio das Américas (ALCA) esteve em pauta, o Mercosul já era considerado prioritário. As palavras do então chanceler Celso Lafer ao afirmar que o Mercosul era um destino, parte das circunstâncias brasileiras, enquanto a ALCA seria uma opção, exemplificam a relevância atribuída ao bloco (Lafer apudVIgevani; Oliveira; Cintra, 2003).

Nesse sentido, Oliveira (2005) sustenta que o governo FHC aprofundou o processo de integração sul-americana por considerar o Mercosul um meio para consecução de objetivos não somente políticos e econômicos, mas também na área de infraestrutura. A dificuldade enfrentada pelo bloco regional entre 1999 e 2002, particularmente relacionada à crise do Real no Brasil, levou o país a optar por abandonar o regime de bandas cambiais, o que provocou a desvalorização da moeda brasileira e, consequentemente, contribuiu para a crise do pagamento da dívida na Argentina, devido ao ganho de competitividade dos produtos brasileiros no mercado portenho.

Em 2000, em um encontro realizado em Brasília, surge a proposta da Iniciativa para Integração da Infraestrutura a Regional Sul-Americana (IIRSA). Era uma tentativa de 
integração física partindo do pressuposto de que a política comercial exclusivamente não seria capaz de aliviar as tensões conjunturais na região, notadamente entre Brasil e Argentina. Em resposta ao movimento cambial brasileiro, a Argentina aumentou seu protecionismo em 2001, que foi prejudicial à tentativa de livre-comércio do Bloco. Buscando uma solução para a crise, vislumbrou-se na promoção de iniciativas que melhorassem a infraestrutura regional como mecanismo, entre outros, direcionados a adensar o escoamento do comércio entre os países da região.

Além disso, houve iniciativas para o fortalecimento normativo do Bloco, como o protocolo da Ushuaia (1998), que estabelece a Cláusula Democrática no Mercosul, com o objetivo de promover a democracia no bloco. Há ainda o Protocolo de Olivos (2002), que introduz o Tribunal Permanente de Revisão (TPR), com o propósito de aperfeiçoar o mecanismo de solução de controvérsias do bloco.

O governo Lula (2003-2010), no entanto, corresponde a um período de recuperação do Mercosul (Visentini, 2012) e (Vigevani; Cepaluni, 2007). É um relançamento da integração regional, principalmente devido à atuação do Brasil, como, por exemplo, Fundo de Convergência Estrutural do Mercosul (FOCEM), com o intuito de combater as assimetrias econômicas entre os membros do bloco.

Buscou-se também o fortalecimento normativo e institucional do bloco por intermédio da criação do Parlamento do Mercosul (Parlasul), em 2006; e com a criação do Instituto Social do Mercosul, que coordenaria e administraria a agenda social do bloco, além da aprovação do Código Aduaneiro, que inclui um acordo para a eliminação da bitributação da Tarifa Externa Comum (TEC) até 2019.

No primeiro governo Dilma (2011-2014) observa-se uma continuidade no que concerne às diretrizes do governo anterior (Cervo; Lessa, 2014). No que se refere ao Mercosul, a presidente Dilma incrementou os acordos na área social do bloco, especialmente no setor educacional. O Brasil apresentou-se ativo no apoio ao Fundo de Financiamento do Setor Educacional do Mercosul (FEM), ao lançamento do Sistema Integrado de Mobilidade Acadêmica no Mercosul (SIM) e à criação Rede Mercosul de Pesquisa. No mesmo sentido, a política externa brasileira foi atuante na regulamentação do Fundo Mercosul de Garantias para empresas de pequeno porte.

Apesar de alguns avanços institucionais relacionados ao Mercosul, conforme supracitado, e da continuidade das diretrizes da $\mathrm{PEB}$ e da condução presente no governo anterior, não se pode afirmar que o primeiro governo Dilma tratou da mesma maneira o Mercosul quando comprado as ações do governo Lula (2003-2010). Uma das diferenças em relação ao governo Lula refere-se, sobretudo, as intensidades das ações. De acordo com Cornetet (2014), os objetivos de desenvolvimento nacional e de consolidação do Brasil como uma potência regional em um mundo multipolar foram mantidos e a estratégia de diversificação de parcerias comerciais e ênfase da cooperação Sul-Sul manteve-se como meio para alcançar esses objetivos, porém os esforços despendidos foram menores.

Isso significa, de acordo com Cornetet (2014), que a política externa de Dilma Rousseff caracterizava-se como a contenção na continuidade. Ou seja, é uma continuida- 
de do que vinha ocorrendo no governo Lula, mas de forma mais contida. Cervo e Lessa (2014) falam em uma "continuidade lerda e frouxa" do primeiro governo Dilma, no sentido da dificuldade do Estado em manter o diálogo intenso e confiante com segmentos da sociedade que haviam colaborado com a ascensão brasileira como potência emergente no governo Lula. Para os autores supracitados, faltou a Dilma Rousseff um diálogo com o empresariado a fim de estimulá-los a investir, gerando quebra de confiança nos investidores nacionais e estrangeiros.

Desse modo, a retração na inserção internacional do Brasil poderia, segundo Cervo e Lessa (2014) ser compreendida a partir do contexto interno. Cervo e Lessa (2014) apontam duas questões que sustentam seu argumento. A primeira refere-se ao sistema político brasileiro de coalizão partidária pelo fato de mudar facilmente de acordo com interesses partidários e pessoais, de modo a afetar a governabilidade. A segunda está relacionada à falta de diálogo e de confiança dos investidores no Estado, à baixa inovação de ideias e à baixa competitividade dos sistemas produtivos e de serviços.

Contudo, há quem defenda a política externa do primeiro mandato de Dilma. É o caso do ex-chanceler Antônio Patriota. Ele afirma que não seria possível manter o mesmo ritmo de ampliação de espaços permanentes, como ocorreu no governo Lula. Para Antônio Patriota, o momento seria para a consolidação dos espaços conquistados, como a UNASUL, a CELAL, e a abertura de 40 novas embaixadas (Bachega, 2014).

Para Stuenkel (2014), o foco da presidente Dilma em tentar resolver problemas relacionados à economia do país somado ao cenário de recuperação econômica internacional e volta da confiança dos Estados Unidos da América (EUA) em sua economia além da suavização de problemas políticos, como a Guerra do Iraque e do Afeganistão, resultaram em uma circunstância mais adversa que, mesmo se o Brasil estivesse sob a presidência de Lula, o presidente teria uma postura mais cautelosa.

Percebe-se, portanto, que a retração na inserção internacional do Brasil, entre 2011 e 2014, pode também ser compreendida como um somatório de condicionantes domésticos e alterações no contexto internacional. Ao assumir o poder, Dilma Rousseff encontrou o país em um momento diferente daquele encontrado por Lula em 2003. A crise econômica iniciada em 2008 e suas consequências é um exemplo da mudança que ocorreu no cenário externo, além da intensificação dos conflitos no Oriente Médio, devido à Primavera Árabe, e em outras regiões do mundo. Esse novo contexto pode ter dificultado uma inserção internacional brasileira mais assertiva (Albanus, 2015).

Isso posto, questiona-se como seria possível um país investir na construção de um espaço geográfico, como a América do Sul, e em uma maior integração entre os Estados desse local, tendo o Mercosul como trampolim e, simultaneamente, resguardar o controle da autonomia de modo que preserve a soberania. O aparente paradoxo é proposital, pois reflete uma postura brasileira articulada politicamente, apesar de não declarada oficialmente.

A autonomia brasileira tem a ver com a ideia da ampliação da margem de atuação ou de escolha do Estado, levando em consideração o contexto interno e o contexto internacional em um determinado período de tempo. Ademais, a autonomia está relacionada 
sempre a uma questão de grau, pois, no caso de uma integração regional como o Mercosul, ele estará implicado, necessariamente, em alguma relativização da autonomia (Vigevani; Ramanzini Júnior, 2014). Baseado nisso pode-se questionar até que ponto (ou qual o grau) o Brasil está disposto a relativizar sua autonomia para aprofundar a integração no Mercosul?

Para responder a esse questionamento exposto, primeiro, é importante ressaltar que apesar de a América do Sul ter-se tornado uma região prioritária para a política externa brasileira, o Mercosul, Bloco que representa majoritariamente os Estados do Cone Sul, surgiu antes da concepção de América do Sul. Ela começou a ser delineada pelo Brasil no governo Itamar Franco (1993-1994), enquanto o Bloco regional foi constituído em 1991, a partir da concertação entre o Brasil e a Argentina, que começaram a se acertar na década de 1980 .

Por ter sido concebido antes da ideia de América do Sul, o Mercosul possui um destaque diferenciado em relação aos outros arranjos desenvolvidos após da concepção da América do Sul, como a União das Nações Sul-Americanas (UNASUL) e a Comunidade dos Estados Latino-Americanos e Caribenhos (CELAL). O processo de integração da América Latina como projeto brasileiro, também no primeiro governo Dilma, tem o Mercosul como mola propulsora e engloba objetivos políticos, sociais e financeiros que ultrapassam a seara econômica e comercial (Cervo; Lessa, 2014).

Para Cervo e Lessa (2014), a visão de mundo brasileira ultrapassa o Mercosul em direção a UNASUL, dessa para CELC e da CELAL para o mundo. Essa visão foi mantida no primeiro Governo Dilma. Isso reflete a ideia de atuação geográfica do Brasil a partir do Cone Sul, aumentando para a América do Sul e, consequentemente, para a América Latina, a fim de dialogar com mais robustez e em conjunto determinados temas com o mundo. A integração regional, por conseguinte, serve como trampolim para a inserção internacional do país. Inserido neste movimento, encontra-se o Mercosul.

O segundo ponto a ser observado para compreender o pragmatismo brasileiro na região é que, além do Mercosul ter surgido antes de outras instâncias, o Bloco, como percebido, faz parte da estratégia brasileira para a região. Embora existam diversos blocos e organizações internacionais na América do Sul e na América Latina, o Mercosul, para o Brasil, não é incompatível com os outros arranjos. Ao contrário, o Mercosul está na base do objetivo brasileiro para a integração regional. Isso pode ser observado nos discursos de Dilma, que serão analisados no próximo tópico.

Nesse sentido, pode-se afirmar que o lugar do Mercosul na política externa brasileira para a América do Sul é de núcleo, como afirmado. É possível afirmar, sem exageros, a ideia de que a política externa brasileira para a América do Sul tem no Mercosul um ponto de partida.

Embora o Mercosul permaneça paralisado do ponto de vista econômico e comercial e, por isso, seja bastante criticado, especialmente a partir dos anos 2000, o Brasil entende que sua defesa constitui uma política de Estado. Isso se deve ao fato que, nos governos de Lula e de Dilma, prevaleceu uma ótica desenvolvimentista, de cunho menos liberal. Desse 
modo, no Mercosul, o viés comercialista foi trocado pelo desenvolvimentista, conforme argumenta Saraiva (2012).

Ao buscar o desenvolvimento, o Brasil contempla o universalismo, o terceiro ponto para compreender o pragmatismo brasileiro na região. De acordo com Lessa (1998), a perspectiva universalista da política externa brasileira tem-se construído paulatinamente desde o final da II Guerra Mundial e solidificou-se, nos anos 1970, no governo Geisel, com o "Pragmatismo Responsável e Ecumênico".

É perceptível a junção entre o que se vem discutindo, o "pragmatismo brasileiro" com o "ecumênico", isto é, a perspectiva universal. Isso significa que o país dialoga com Estados sem distinção e em todos os continentes. Não por acaso a afirmação disponível no Portal Oficial do Itamaraty (2015) que, desde 2011, primeiro ano do governo Dilma, o Brasil mantém relações diplomáticas com todos os países da ONU, o que comprova a afirmação acima.

Manter relações diplomáticas com vários países não significa, no entanto, afinidades intensas com todos eles. De acordo com Lessa (1998), em sua rede de relações bilaterais, construída ao longo das décadas, o Brasil foi seletivo com alguns, ao ponto de estabelecer parcerias estratégicas com intensidade maior e ganhos concretos para os dois lados. Essas vantagens conquistadas pelo país são fundamentais para o desenvolvimento econômico.

Ao se relacionar com uma maior quantidade de países, o Brasil atrai maiores oportunidades de investimentos, comércio, conhecimentos tecnológicos, financiamentos, ou seja, estabelece mecanismos direcionados ao desenvolvimento nacional. De acordo com Lessa (1998), o universalismo, desde os seus primórdios, foi temperado por boa dose de pragmatismo.

O pragmatismo brasileiro na América do Sul está justamente no fato de o país não incentivar o aprofundamento institucional das instâncias regionais, a fim de não se vincular de uma forma que comprometa sua ação individual nas outras partes do mundo. Se o Brasil, como o principal país da região, estimulasse essa iniciativa, isto implicaria ceder soberania, o que não parece ser do interesse do país.

Essa estratégia está associada à racionalidade da posição do Brasil em defesa do princípio de autonomia do Mercosul no que se refere a defesa da intergovernabilidade enquanto princípio institucional da integração, que é oposição à ideia de aprofundamento (Vigevani; Ramanzini Júnior, 2014). Esse é um ponto importante para compreender o pragmatismo brasileiro, pois se opta por um Mercosul livre de amarras, diferentemente se o mesmo fosse regido pelo princípio da supranacionalidade, como ocorre na União Europeia (UE).

Nesse sentido, o Mercosul estaria condicionado a permanecer uma união aduaneira imperfeita e não avançaria para o estágio de mercado comum, que é seu objetivo, pois significaria uma maior perda do grau da autonomia. Isso ocorreria porque, de acordo com Balassa (2011), para avançar ao estágio de Mercado Comum, haveria a necessidade de circulação de fatores de produção entre os Estados-partes, o que implicaria em aceitação de mais regras comuns. Também não recuaria para o estágio de livre-comércio, pois 
é do interesse do Brasil manter os membros do Bloco unidos, proporcionar estabilidade política e cooperar para o desenvolvimento recíproco.

Deixar o Mercosul como União Aduaneira, portanto, está associado aos dois princípios que norteiam a política externa brasileira: universalismo e autonomia. Desse modo, pode-se entender o quarto ponto que explica o pragmatismo brasileiro na região. Os dois princípios permitem ao Brasil agir no cenário internacional com certa independência e com todos os países que interessar.

Cervo e Lessa (2014) apontam que, embora o Mercosul seja impulsionador da integração regional, o Bloco está em processo de construção de forma indefinida e essa lógica continua no governo Dilma. Os autores demonstram que isso representa a essência do processo de integração da América Latina, cujo objetivo é não ceder o controle da autonomia a ponto de debilitar a soberania. Trata-se de uma questão de cultura política.

De acordo com Klemi e Menezes (2016), mesmo com o giro à esquerda e pós-neoliberal dos países da América do Sul, a partir da década de 2000 e sob a égide neodesenvolvimentista, não foi possível criar as condições plenas para uma integração regional na América do Sul. Além da cultura política da região, o posicionamento do Brasil de não querer relativizar mais seu grau de autonomia reflete nesse processo, pois o país é um ator importante na região.

Nesse sentido, o Mercosul está na base de todo esse processo estratégico, mesmo sendo utilizado dentro de um limite imposto pela ação ambígua da diplomacia brasileira que se utiliza do Mercosul como um instrumento para a sua inserção internacional, mas não é tão explícita sobre como melhorar o processo de integração, tornando o Bloco regional em estado permanente de um "processo em construção", pois é do interesse do Brasil preservar sua autonomia e soberania.

Por isso, é perceptível, no discurso diplomático brasileiro, não somente ao modo implícito pelo qual o Mercosul é tratado especialmente quando se refere a melhorar o processo de integração, mas também o modo explícito quando se refere ao aprofundamento do Bloco regional para melhor inserir-se no cenário internacional.A ambiguidade está refletida nos discursos oficiais. Parte-se então para a análise conforme apresentada na introdução do texto.

\section{A análise do termo Mercosul no discurso diplomático no contexto bilateral}

A Análise do Discurso busca compreender a produção de efeitos de sentido, realizada por sujeitos sociais, que usam a materialidade da linguagem e estão inseridos na história (Gregolin, 2007). É interessante perceber que um discurso somente faz sentido porque ele está inserido em um contexto histórico específico, pois, do contrário, não produziria tantos efeitos. 
Desse modo, de acordo com Onuf (2002), seres humanos constroem a realidade por meio de ações. Essas ações podem ser discursos (atos de fala). Discursos, por sua vez, por meio de repetições, podem ser institucionalizados em regras e, assim, fornecer o contexto e a base para a ação humana. Essa base de ação pode, no caso estabelecido para análise, ser observada em números, a partir da distribuição dos discursos pronunciados pela presidente Dilma Rousseff em que o termo Mercosul foi mencionado como segue na Tabela 1.

Tabela 1: Distribuição dos discursos da presidente Dilma, por contexto, no qual a palavra Mercosul tenha sido citada ao menos uma vez durante o Primeiro Mandato

\begin{tabular}{|c|c|c|c|c|}
\hline Ano & $\begin{array}{c}\text { Pronuncia- } \\
\text { mentos } \\
\text { Oficiais }\end{array}$ & $\begin{array}{c}\text { Contexto } \\
\text { bilateral }\end{array}$ & $\begin{array}{c}\text { Contexto } \\
\text { Multilateral }\end{array}$ & $\begin{array}{c}\text { Contex- } \\
\text { to Interno }\end{array}$ \\
\hline 2011 & 21 & 8 & 6 & 7 \\
\hline 2012 & 16 & 8 & 8 & 0 \\
\hline 2013 & 19 & 12 & 3 & 4 \\
\hline 2014 & 14 & 2 & 7 & 5 \\
\hline Total geral & $\mathbf{7 0}$ & $\mathbf{3 0}$ & 24 & 16 \\
\hline
\end{tabular}

Fonte: Elaborado pelos autores, baseado no sítio oficial do Palácio do Planalto (2015).

Percebe-se na tabela acima que o Mercosul foi citado mais no contexto bilateral do que no contexto multilateral e que o ano de 2011, primeiro ano do mandado da presidente Dilma Rousseff, foi o mais intenso em relação à quantidade de discursos no qual a palavra Mercosul tenha sido citada. Houve uma escolha para onde falar do Mercosul e a motivação. De certa forma os dados corroboram as afirmações expostas no primeiro tópico do texto. O Mercosul é relevante, é considerado como uma plataforma estratégica política e econômica, mas limitado regionalmente.

Pode-se ainda adensar a exposição de motivos. Basta observar que dentre 30 discursos pronunciados em um contexto bilateral pela presidente da República, a palavra Mercosul tenha sido citada em 14 destes, em reuniões/encontros bilaterais com países sul-americanos. Desses, seis foram no contexto das relações bilaterais com a Argentina. Com a tabela abaixo, é possível observar esses números destrinchados.

Tabela 2: Distribuição dos discursos da presidente Dilma em um contexto bilateral durante o Primeiro Mandato em que tenha citado o Mercosul ao menos uma vez.

\begin{tabular}{|c|c|c|c|c|c|}
\hline Ano & $\begin{array}{c}\text { Contexto } \\
\text { bilateral }\end{array}$ & $\begin{array}{c}\text { Brasil - paí- } \\
\text { ses sul-a- } \\
\text { mericanos } \\
\text { (exceto } \\
\text { Argentina) }\end{array}$ & $\begin{array}{c}\text { Brasil - Ar- } \\
\text { gentina }\end{array}$ & $\begin{array}{c}\text { Brasil - paí- } \\
\text { ses europeus }\end{array}$ & Outros \\
\hline 2011 & 8 & 2 & 3 & 2 & 1 \\
\hline 2012 & 8 & 1 & 1 & 4 & 2 \\
\hline 2013 & 12 & 5 & 2 & 3 & 2 \\
\hline
\end{tabular}




\begin{tabular}{|c|c|c|c|c|c|}
\hline 2014 & 2 & 0 & 0 & 2 & 0 \\
\hline Total geral & 30 & 8 & 6 & 11 & 5 \\
\hline
\end{tabular}

Fonte: Elaborado pelos autores, baseado no sítio oficial do Palácio do Planalto (2015).

Essa desigualdade em relação aos outros países da região não pode ser considerada aleatória, dada a importância do vínculo estratégico entre Brasil e Argentina. Foi a partir do estreitamento de relações entre os dois países, no final dos anos 1970, que possibilitou o surgimento do Mercosul, em 1991, com o Tratado de Assunção. O Brasil e a Argentina possuem hoje uma Aliança Estratégica Global quando se toma um modelo de análise pragmático.

Não por acaso, a primeira visita presidencial ao exterior de Dilma foi a Argentina, em 31 de janeiro de 2011. Em seu pronunciamento oficial, a presidente se referiu ao Mercosul apenas uma vez. Ela reforçou a importância do bloco regional, juntamente com a União das Nações Sul-Americanas (UNASUL), para o desenvolvimento dos povos da América Latina. Isso perpassa a ideia de que o Mercosul vai além do seu entorno geográfico, o Cone Sul, e alcança maiores proporções, envolvendo a América do Sul e a América Latina. Não na forma de um constructo comercial, mas como uma base política estratégica.

No mesmo dia, a presidente fez outro pronunciamento, ao almoçar com a presidente da Argentina à época, Cristina Kirchner. Dessa vez, Dilma falou de forma mais específica sobre o Mercosul ao mencionar o crescimento do comércio bilateral e do investimento, relacionando-os à integração econômica proporcionada pela cooperação no bloco regional. Em um segundo momento, a presidente sugere o aprofundamento e o fortalecimento do Bloco em uma União Aduaneira e em suas agendas sociais e produtivas.

De acordo com Saraiva (2008), as diferentes percepções e diferentes projetos sobre o que deveria ser o Bloco limitam seu aprofundamento e sua consolidação. A autora argumenta que, na Argentina, o fato de haver a possibilidade de dependência em relação ao Brasil, os riscos de se ter um parceiro instável economicamente, o nacionalismo e a autonomia brasileira são temas debatidos entre os articuladores políticos argentinos que, em relação ao Mercosul, são o Ministério da Fazenda e as Relações Exteriores.

Nesse sentido, a presidente brasileira menciona o comércio e o investimento como fatores relevantes para a relação entre as nações. Segundo o Ministério do Desenvolvimento, Indústria e Comércio Exterior do Brasil (2014), a Argentina é o terceiro maior parceiro comercial do Brasil além de o Brasil ser o maior investidor direto na Argentina.É do interesse do Brasil manter esse nível de comércio e investimento. Já no que concerne a busca de uma pauta social mais robusta para o Mercosul é um discurso que tem origem e ganha força no governo Lula e tem continuado em Dilma.

A fim de reforçar suas falas anteriores, a presidente Dilma, em um discurso de julho de 2011, no Itamaraty, junto com Cristina Kirchner, reafirmou o compromisso com a integração regional via Mercosul e, a partir disso, o estabelecimento de uma relação dinâmica com os países da região. É interessante observar que a presidente já cita a UNASUL nesse contexto, o que sugere um propósito de empoderamento da UNASUL. 
Houve somente um discurso, proferido em 2012, em que a presidente citou o Mercosul. Ao todo, a palavra foi mencionada cinco vezes. Foi no encerramento da Conferência Industrial Argentina. A primeira menção foi sobre a importância da entrada da Venezuela no Bloco, tema que será tratado mais na frente. Em seguida, Dilma reafirma a relevância da relação bilateral para a consecução do Mercosul e, mais adiante, destaca o FOCEM, a próxima cúpula do Bloco a ocorrer, junto com a $1^{\circ}$ Fórum Empresarial do Mercosul.

Em 2013, ocorreram dois encontros com a presidente da Argentina nos quais a presidente Dilma cita o Mercosul. Um após um encontro oficial e outro em um jantar. Foram dois discursos e quatro citações, nesse contexto, em 2013. No primeiro, Dilma relata a importância estratégica do Mercosul, da UNASUL e, dessa vez, ela cita a Comunidade dos Estados Latino-Americanos e Caribenhos (CELAL). Aqui é interessante observar a ordem em que as palavras foram mencionadas no discurso.

Nós temos um papel que eu considero cada vez mais, um papel estratégico quando se trata dos órgãos multilaterais: Mercosul, UNASUL e CELAL. Aliás, lembrando o processo de constituição desses organismos nós temos sempre que saudar a fantástica contribuição dada por dois latino-americanos - Néstor Kirchner e Luiz Inácio Lula da Silva - quando se trata da construção dessa perspectiva multilateral de desenvolvimento, de atuação, e o papel democrático que estes órgãos têm desempenhado aqui na região. ${ }^{2}$

A estratégia é de cunho geográfico. Existe uma lógica ao colocar o Mercosul em primeiro ao tratar dos órgãos multilaterais e isso está refletido no discurso. Este Bloco circunscreve o Cone Sul (Brasil, Argentina, Uruguai e Paraguai). Depois, Dilma cita a UNASUL, que envolve todos os países da América do Sul. E, por fim, a CELAL, que envolve todos os países da América Latina e Caribe. Dilma segue uma ordem cronológica ao citar as instituições.

Nas outras citações, a presidente reitera a importância destes órgãos e conclama para a continuação do diálogo na Cúpula do Mercosul que ocorreu em Montevidéu. Já no ano de 2014, não houve pronunciamento de discursos oficiais no contexto da relação bilateral entre Brasil e Argentina no qual a presidente da República tenha citado a palavra ao menos uma vez.

É relevante perceber até aqui a dimensão intersubjetiva das relações internacionais, no sentido de que os discursos somente possuem algum significado porque se encontram em determinado contexto compartilhado por uma coletividade. De acordo com Kratochwil (1989), o contexto é mediado por normas e regras que moldam as decisões dos atores. Não deve causar estranheza supor que Dilma evitaria pronunciar em um discurso que sugerisse uma dependência econômica da Argentina. Tal ação quebraria a estratégia que fundamenta o discurso.

As regras e as normas consolidadas na relação entre ambos os países permite supor que tomadores de decisão e seu staff imaginem a construção do discurso dentro de um

2 Discurso da presidente da República, Dilma Rousseff, durante declaração à imprensa após reunião de trabalho com a presidente da Argentina, Cristina Kirchner - Buenos Aires, Argentina, 25/04/2013. 
propósito. É desse modo que são construídas e fortalecidas as medidas tomadas entre os Estados. É a partir do uso da linguagem que surgem as ideias, depois as regras se constituem e, assim, a decisão é tomada no cenário internacional, embora não a determinem por completo, como afirma Kratochwil (1989).

A partir disso, é possível compreender o porquê do Brasil priorizar, ao longo do primeiro mandato da presidente, falar mais sobre o Mercosul com a Argentina do que com os outros países. De acordo com os pronunciamentos disponíveis no Portal Oficial do Palácio do Planalto (2014), o segundo país no qual a presidente mais dialogou sobre Mercosul na América do Sul, em seus discursos oficiais, foi o Paraguai, com três discursos no qual a palavra foi citada. Em seguida a Venezuela e o Uruguai, com dois discursos cada.

Com o Paraguai, a mandatária brasileira fez o primeiro discurso oficial, no contexto bilateral, no qual o Mercosul foi citado somente em 2013. Parte da demora em incluir o Paraguai na agenda está relacionada com o ocorrido em 2012, com o então presidente Fernando Lugo, que sofreu um processo de impeachment pelo Senado do país. Os Estados-partes do Mercosul consideraram o processo como o golpe de Estado e resolveram utilizar a cláusula democrática para suspender o Paraguai do Mercosul até que novas eleições ocorressem.

A posse do novo presidente paraguaio, Horácio Carter, somente ocorreu em agosto de 2013. A partir desse fato, um mês depois, em setembro, a presidente recebe a visita oficial do presidente paraguaio eleito. Retomando o aspecto estratégico atribuído aqui aos pronunciamentos, observou-se que na primeira declaração que envolve o Mercosul tenha como ponto principal a hidrelétrica binacional de Itaipu. Tema este dotado de relevância para o Paraguai que utilizava (2014) 75,1\% da energia gerada pela hidrelétrica. Esse ponto não deixa de ser relevante para o Brasil por todo o processo que envolve os acordos relacionados à hidrelétrica binacional de Itaipu ${ }^{3}$.

Dilma afirmou que a conclusão de uma linha de transmissão que levará mais energia de Itaipu para os arredores de Assunção, capital paraguaia, foi possível devido à ajuda do FOCEM que, de acordo com o Portal Oficial do Ministério do Planejamento e Gestão (2014), o Brasil contribuiu com 70\% dos recursos para o fundo, enquanto que a Argentina 27\%, Uruguai 2\% e Paraguai 1\%. Essa divisão é feita segundo o peso econômico do Produto Interno Bruto (PIB) de cada país do bloco.

Em seguida, a presidente citou o Mercosul em mais quatro ocasiões em um único parágrafo do discurso. Todas elas têm a ver com a volta do Paraguai ao Bloco, depois da suspensão sofrida. A presidente disse que a participação do Paraguai era importante no Mercosul e justifica sua afirmação emendando uma questão geográfica e outra do ponto de vista institucional do Bloco. Novamente, pode-se observar que o Mercosul tem uma força política no discurso oficial superando até mesmo seus objetivos econômicos.

3 Sugere-se a leitura do texto de autoria de Tomaz Espósito Neto. O tortuoso caminho da cooperação entre Brasil e Argentina: De Itaipu ao Mercosul. Conjuntura Austral, v. 4, p. 54-69, 2013; e complementarmente, do mesmo autor, a tese de doutoramento intitulada "Itaipu e as relações brasleiro-paraguaias de 1962 a 1979: fronteira, energia e poder". 
Dilma ainda fala que a volta do Paraguai é importante para integração, pois possibilitaria um movimento de integração partindo da Patagônia ao Caribe com a entrada da Venezuela no Bloco. Ou seja, a volta do Paraguai ocupará um espaço deixado próximo a Patagônia, enquanto que a entrada da Venezuela no Bloco permitirá o acesso ao Caribe. Por fim, em uma última citação, Dilma afirma que, devido a isso, o Paraguai é um parceiro estratégico, seja no Mercosul, na UNASUL e bilateralmente.

Ainda no mesmo dia, Dilma fez outro discurso oficial durante um almoço com o presidente paraguaio, reiterando a importância do processo de integração regional para os países da América Latina. Aqui não se fala de modo específico do Paraguai, embora seja um discurso feito para esse país. A presidente diz que a integração beneficiará no desenvolvimento dos Estados da região. E, portanto, pode-se inferir que a premissa do desenvolvimento presente no discurso político brasileiro está diretamente associada à dinâmica de integração regional.Vale ressaltar que a despeito da manutenção as diretrizes da PEB, há uma inflexão observada no governo Lula, principalmente, e no governo Dilma, de forma mais tímida, cujos olhares e atenção para os países da região são, simultaneamente, estratégia de inserção e premissa ideológica.

O último discurso, no qual citou o Mercosul com o Paraguai foi justamente no dia na inauguração da linha de transmissão que proporcionaria mais energia de Itaipu para os arredores da cidade de Assunção. Dilma citou o Mercosul quatro vezes nessa ocasião. A primeira relembrou que o projeto somente foi viável devido ao FOCEM.A segunda está ligada à primeira, pois enaltece o propósito do FOCEM (cujo maior investidor é o Brasil) de contribuir nos esforços para diminuir as assimetrias da região, indo além do comércio.

As outras duas vezes em que o termo foi citado tiveram relação com a preocupação do Brasil em demonstrar que os órgãos multilaterais, especialmente os impulsionados pela diplomacia brasileira, não são incompatíveis (Saraiva, 2013). O discurso passa a imagem de que a existência do Mercosul não corresponde a um empecilho para a UNASUL. Na verdade, eles são complementares, embora atuem em diferentes esferas. Enquanto o primeiro surgiu com o foco econômico, o segundo tem um tom mais político.

Ao colocá-los juntos, a presidente associa a outra vertente da diplomacia brasileira de forma mais intensa desde a EraVargas: usar a política externa para a busca do desenvolvimento (Cervo; Bueno, 2008). Nessa ocasião, a presidente reiterou ao Paraguai que, por meio da contribuição dos órgãos de política regional, possibilitar-se-ia o desenvolvimento da infraestrutura, da ampliação dos mercados e garantia de marcos regulatório, sempre tendo como ponto de partida a integração Sul-Sul.

Nesse sentido, por serem complementares, nada impede que o Mercosul tenha uma dimensão política. Isto é, nada impede de ser mais um instrumento que o Brasil utiliza para a consecução de seus objetivos. E é justamente o que está sendo discutido neste artigo. Isso é uma diretriz constitutiva da política externa brasileira que tem sido reiterada diante dos países da América do Sul, principalmente, por meio de discursos oficiais que envolvam o Mercosul no contexto bilateral. Com a Venezuela não foi diferente. 
Foram apenas dois discursos e duas citações em quase quatro anos de governo, a partir da contagem feita pelo Portal do Palácio do Planalto (2014). No primeiro pronunciamento oficial, a fim de criar uma atmosfera de identidade frente ao presidente Hugo Chávez, em junho de 2011, a presidente Dilma começou o discurso falando sobre política social. Chegou ao tópico Mercosul depois de falar da importância da integração regional. A presidente destacou que aguardava com grande expectativa a entrada da Venezuela no Bloco.

A entrada da Venezuela no Mercosul foi importante para o Brasil. Segundo o Portal do Ministério das Relações Exteriores do Brasil (2014), ao integrar o Mercosul na qualidade de membro pleno, a Venezuela permitiu que o bloco contemplasse $70 \%$ da população e $80 \%$ do PIB da América do Sul. Além disso, facilitaria o acesso e o escoamento até a região do Caribe.

O Protocolo de Adesão daVenezuela ao Mercosul foi assinado em 2006. Em 2009, o Congresso brasileiro aprova a entrada do país no Bloco. E, até meados de 2012, somente o Senado paraguaio ainda não havia ratificado o ingresso da Venezuela. Mas, tudo mudou em julho de 2012. Após o então presidente paraguaio, Fernando Lugo, sofrer o processo de impeachment, os Estados-partes do Mercosul consideraram o ato como golpe de Estado e suspenderem o Paraguai do Bloco.

Nesse ínterim, Brasil, Uruguai e Argentina decidiram confirmar a Venezuela como membro pleno do Mercosul. Já que o Paraguai estava suspenso, não dependiam mais da aprovação do Senado paraguaio. Polêmicas à parte, o que interessa aqui é o fato de aVenezuela ser incorporada ao Mercosul por iniciativa do Brasil e que já havia essa expectativa desde o primeiro discurso de Dilma em 2011.

O segundo discurso tendo a Venezuela como foco no qual o Mercosul foi citado ocorreu em maio de 2013, praticamente um ano depois de sua entrada no Bloco e após a morte de Hugo Chávez, em março do mesmo ano. A presidente Dilma disse que o Mercosul entraria em um momento histórico pelo fato de, pela primeira vez, o Bloco regional ter a presidência protempore sob o comando daVenezuela. Essa declaração confirma a vontade do Brasil em ter a Venezuela integrada ao Bloco.

No parágrafo seguinte, embora não cite o Mercosul diretamente, vale a pena registrar que, mais uma vez, a presidente fez questão de mencionar a UNASUL e o processo de integração regional da América do Sul. Ela geralmente ressalta a importância das coalizões e dos países que a compõem. É um encadeamento do pensamento ao associar Mercosul à UNASUL, à integração, ao desenvolvimento e aos povos da América Latina e do Caribe. Isso faz todo sentido para a política externa brasileira ao se observar a ideia de círculos concêntricos desenvolvida por Simões (2011), em que a Argentina é a base do círculo base e o Mercosul é o núcleo dessa inserção internacional do país.

Em relação ao Uruguai, a presidente pronunciou apenas um discurso no qual citou o Mercosul duas vezes, no mesmo parágrafo, em maio de 2011, em Montevidéu. A primeira diz respeito aos vinte anos do Mercosul, que surgiu em 1991. Após isso, a presidente diz que o Bloco ganha destaque, porque contribui para que a América do Sul tenha 
sido uma das regiões que mais cresceu do mundo. Em seguida, de forma estratégica, cita também a UNASUL e o processo de integração regional.

\section{Considerações finais}

O objetivo deste artigo foi discutir o uso do termo Mercosul como meio para a inserção internacional do Brasil a partir dos discursos oficiais pronunciados pela presidente Dilma Rousseff, feitos em um contexto de relação bilateral com os países da América do Sul. Notou-se que os discursos estavam, nessa região, concentrados, praticamente, nos países que compõem o Mercosul.

Conforme exposto ao longo do artigo, nota-se, portanto, que vários discursos foram pronunciados em lugares diferentes do mundo para diferentes interlocutores. Desse modo, além de ser fundamental prestar atenção naquilo que está no discurso, também é importante atentar para as ausências que podem ser tão importantes quanto o próprio discurso. Ou seja, o que a presidente Dilma Rousseff poderia ter dito, mas não disse? Quais assuntos que envolvam o Mercosul e não estiveram presentes durante os seus 30 discursos feitos em contexto bilateral?

Em relação aos discursos pronunciados com alguns países da América do Sul constata-se algo incoerente. Se o Mercosul, para o Brasil, é o núcleo da integração regional, não faz sentido Dilma falar dele somente com os países que compõem o Bloco regional, como foi o que ocorreu em seu primeiro mandato. Segundo consta no Portal da Secretaria de Comunicação Social da Presidência da República (2014), ao longo dos quatro anos de mandato, Dilma esteve, além dos países já citados, no Suriname, no Chile, Cuba e México.

Por mais que haja países com mais ou menos intensidade na relação diplomática, seria interessante falar do Mercosul em todas as visitas que fossem feitas pela América Latina. Afinal, se o bloco é considerado pelo Brasil o cerne do processo de integração regional, contribui para o desenvolvimento por meio do comércio e, consequentemente, tem papel relevante na aproximação política regional, esperava-se mais ênfase na divulgação das ações intrabloco.

Com os outros países seria importante citar mais vezes o Mercosul nos discursos oficiais. Ou seja, vender a ideia de ação do bloco seria uma forma de iniciar mais diálogos com outras regiões, para concluir acordos comerciais e também políticos.

Nota-se que, de fato, as ausências são, às vezes, tão importante quanto as presenças. No caso do Brasil, os discursos oficiais de Dilma em que ela mencionou ao menos uma vez a palavra Mercosul representam 9,53\% do total de discursos feitos no primeiro mandato. Já no contexto bilateral representam 4,34\% do total. Está claro que há margem para transformar as ausências em presenças e, desse modo, contribuir mais com a inserção internacional do Brasil.

As ausências de Dilma no que se refere ao diálogo mais assertivo, embora ele seja objetivo, pode ser explicado com a observação de Cervo e Lessa (2014) quando afirmam 
que houve um declínio da inserção internacional do Brasil e, um dos motivos, foi a dificuldade de diálogo do Estado.

Desse modo, o teor dos discursos de Dilma foi pragmático ao defender as demandas brasileiras, especialmente aquelas de cunho econômico. Na América do Sul, em geral, falou-se sobre o Mercosul ao associá-lo como uma parte importante do processo de integração do continente para atingir o desenvolvimento. Não é coincidência que quase sempre que o Mercosul era citado por Dilma, a UNASUL também era.

Por fim, vale a pena ressaltar que todos os discursos da presidente Dilma que foram analisados neste trabalho não tratavam especificamente do Mercosul, mas sim citado, como parte integrante do discurso, quase complementar. Ou seja, o Bloco regional não foi o tema principal dos discursos da amostra. Ainda assim, é possível afirmar que o Brasil utiliza-se do Mercosul como uma via para se inserir internacionalmente com o intuito de fomentar, discutir, cobrar, destacar e enaltecer suas demandas na política internacional.

\section{Referências}

ALBANUS, Adriana Pilar Ferreira. "Continuar não é repetir" a política externa dos governos Lula e Dilma em perspectiva comparada. NEIBA, v. IV, n. 1, 2015.

AMORIM, Celso. Brazilian Foreign Policy under President Lula (2003-2010): an overview. Revista Brasileira de Política Internacional. v. 53, Edição Especial, Brasília, dez. 2010.

BACHEGA, Hugo. Patriota nega recuo de política externa e diz que 'era hora de consolidar'. BBC Brasil, São Paulo, 22 maio 2014. Disponível em:< http://www.bbc.com/portuguese/noticias/2014/05/140513_entrevista_ patriota_hb>.Acesso em: 21 nov. 2014.

BALASSA. Béla. The Theory of Economic Integration. Califórnia: Editora Routledge, 2011.

BRASIL. Dados oficiais sobre o Fundo de Convergência do Mercosul. 2014a. Disponível em: <http://www. planejamento.gov.br/ministerio.asp?index=10\&ler=t3431> Acesso em: $20 \mathrm{dez} .2014$.

Ministério da Indústria, Comércio Exterior e Serviços. Dados oficiais sobre o comércio exterior brasileiro. 2014 b. Disponível em: <http://www.mdic.gov.br/sitio/interna/noticia.php?area=1\&noticia=13043>. Acesso em: 20 dez. 2014.

BRASIL. Ministério das Relações Exteriores. Discurso da Presidente da República na Argentina, Buenos Aires, 25 abr. 2013. Acesso em 05/12/2014.

. Ministério das Relações Exteriores. Política Externa. Mercosul. Disponível em: < http://www.itamaraty. gov.br/pt-BR/politica-externa/integracao-regional/686-mercosul >. Acesso em: 21 dez. 2014.

Palácio do Planalto. Presidência da República. Mandatos de Dilma Rousseff (2011-2014) - discursos Mercosul. 2014. Disponível em <http://www2.planalto.gov.br/acompanhe-o-planalto/discursos\#b_ start $=0 \& \mathrm{c} 1=$ mercosul $>$. Acesso em: $22 \mathrm{dez} .2014$.

Palácio do Planalto - Presidência da República. Relatórios da Secretaria de Imprensa. 2014. Disponível em: <http://www2.planalto.gov.br/area-de-imprensa/relatorios-da-secretaria-de-imprensa/relatorios-dasecretaria-de-imprensa>. Acesso em: $21 \mathrm{dez} .2014$.

CERVO, Amado; LESSA, Antônio Carlos. O declínio: inserção internacional do Brasil (2011 - 2014). Revista Brasileira de Política Internacional, n. 57, Brasília, 2014.

; BUENO, Clodoaldo. História da Política Exterior do Brasil. Brasília: Editora Universidade de Brasília, 2008. 
CORNETET, João Marcelo Conte. A Política Externa de Dilma Rousseff: contenção na continuidade. Revista Conjuntura Austral, v. 5, n. 24, 2014.

ESPÓSITO NETO, Tomaz. Itaipu e as relações brasleiro-paraguaias de 1962 a 1979: fronteira, energia e poder. 2012. 322 f. Tese (Doutorado em Ciências Sociais) - Ciências Sociais, Pontificia Universidade de São Paulo, 2012.

. GREGOLIN, Maria do Rosario. Análise do discurso e mídia: a (re)produção de indentidades. Comunicação, mídia e consumo, v. 4, São Paulo, 2007.

ITAIPU BINACIONAL. Perguntas Frequentes. Disponível em: <https://www.itaipu.gov.br/sala-de-imprensa/ perguntas-frequentes>. Acesso em: dez. 2014

KLEMI, Albeni Miriam Menezes; MENEZES, Roberto Goulart. Brasil e Mercosul: rumos da integração na lógica do neodesenvolvimentismo (2003 - 2014). Revista Caderno CHA, Salvador, v. 29, n. 3, 2016.

KRATOCHWILL, Friedrich. Rules, Norms, and Decisions. On the conditions of practical and legal reasoning in international relations. Cambridge: University Press, 1989.

LESSA, Antônio Carlos. A diplomacia universalista do Brasil: a construção do Sistema contemporâneo de relações bilaterais. Revista Brasileira de Política Internacional, v. 41, 1998.

MILLIKEN, Jennifer. The Study of Discourse in International Relations: A Critique of Research and Methods. European Journal of International Relations, SAGE, 1999.

NOGUEIRA, Conceição. A análise do discurso. In: FERNANDES, Eugênia M.; ALMEIDA, Leandro S. (Org.). Métodos e técnicas de avaliação: novos contributos para a prática e investigação psicológicas. Braga: Universidade do Minho, 2001.

OLIVEIRA, Henrique Altemani de. Política externa brasileira. São Paulo: Saraiva, 2005.

ONUKI, Janina. "O Brasil e a construção do Mercosul". In: OLIVEIRA, Henrique Altemani de; LESSA, Antônio Carlos (Org.). Relações Internacionais do Brasil: temas e agendas. São Paulo: Saraiva, 2006.

ONUF, Nicholas. Worlds of our making. The strange career of constructivism in International Relations. In: PUCHALA, Donald J. (Ed.). Visions of International Relations. Columbia: University of South Caroline Press, 2002.

SARAIVA, Miriam Gomes. As relações Brasil - Europa de 1990 a 2004. In: OLIVEIRA, Henrique Altemani de ;LESSA, Antônio Carlos (Org.). Relações Internacionais do Brasil: temas e agendas. São Paulo: Saraiva, 2006.

. As diferentes percepções na Argentina sobre o Mercosul. Revista Contexto Internacional, v. 30, Rio de janeiro, 2008.

. Brazilian foreign policy towards South America during the Lula Administration: caught between South America and Mercosur. Revista Brasileira de Política Internacional, v. 53, Brasília, 2010.

. Procesos de integración de América del Suryel papel de Brasil: los casos del Mercosur e laUnasur. Revista CIDOB d'afers internacionals, n. 97-98, 2012.

Novas abordagens para análise dos processos de integração na América do Sul: o caso brasileiro. Revista Contexto Internacional, v. 08, Rio de Janeiro, 2013.

SIMÕES, Antônio José Ferreira. Integração: sonho e realidade na América do Sul. Brasília: Funag, 2011.

STUENKEL, Oliver. Como a volta de Lula mudaria a política externa brasileira? Post-Western World. 15 jun. 2014. Disponível em:< http://www.postwesternworld.com/2014/06/15/politica-externa-brasileira/>. Acesso: 10 jan. 2016.

VIGEVANI, Tullo; CEPALUNI, Gabriel. A Política Externa de Lula da Silva: A Estratégia da Autonomia pela Diversificação. Revista Contexto Internacional, v. 29, 2007.

; OLIVEIRA, Marcelo F. de; CINTRA, Rodrigo. Política externa no período FHC: a busca de autonomia pela integração. Revista Tempo Social, USP, v. 15, n. 2, 2003.

; RAMANZINI JÚNIOR, Haroldo. Autonomia, Integração Regional e Política Externa Brasileira: Mercosul e UNASUL. Revista de Ciências Sociais, v. 57, n. 2, 2014. 
; RAMANZINI JÚNIOR, Haroldo. Autonomia e integração regional no contexto do Mercosul:uma análise considerando a posição do Brasil. Observatório Social de América Latina, v. XI, n. 27, p. 45-63, 2010. Disponível em: <http://hdl.handle.net/11449/115349>. Acesso em: 14 dez. 2015.

VISENTINI, Paulo Fagundes. A projeção internacional do Brasil: 1930 - 2012. Rio de Janeiro: Elsevier, 2012.

WENDT,Alexander. Collective identity formation and the international state. American Political Science Review, v. $88,1994$. 


\section{The Mercosur in the brazilian diplomatic discourse of Dilma's first government (2011-2014) in bilateral context}

\section{Abstract}

The objective of this article is to discuss the use of the term Mercosur in the diplomatic discourse of the 1st government speech Dilma Rousseff (2011-2014) in a bilateral context with the countries of South America.In order to understand the dynamics, the Brazilian Foreign Policy guidelines will be used, as Universalism and Autonomy, and Discourse Analysis methodology, in order to check the context in which the word is insered, the interlocturs involved and the implicit and explicit motivations. The article will show that the discourse is one of the means for the international insertion of Brazil.

Keywords: MERCOSUR, discourse analysis, Brazilian Foreign Policy, Dilma’s Government.

\section{El Mercosur en el discurso diplomático del $1^{\circ}$ gobierno Dilma (2011-2014) en contexto bilateral}

\section{Resumen}

El objetivo del artículo es discutir el uso del término MERCOSUR en el discurso diplomático del primer gobierno Dilma Rousseff (2011-2014) en un contexto bilateral con los países de América del Sur. Con el propósito de entender la dinámica, serán utilizadas directrices de la Política Externa Brasileña, como Universalismos y Autonomía, y la metodología del Análisis del Discurso, con el fin de verificar el contexto en el que la palabra está insertada, los interlocutores envueltos y los motivos implícitos y explícitos. El artículo denotará que el discurso es un medio para la inserción internacional de Brasil.

Palabras clave: MERCOSUR, análisis del discurso, la política exterior brasileña, gobierno Dilma. 
